\title{
Guideline Adherence and Registry Recruitment of Congenital Primary Hypothyroidism: Data from the German Registry for Congenital Hypothyroidism (HypoDok)
}

\author{
Julia Thomann ${ }^{1,}{ }^{*}$, Sascha R. Tittel ${ }^{2}$, Egbert Voss ${ }^{3}$, Rudolf Oeverink ${ }^{4}$, Katja Palm ${ }^{5}$, Susanne Fricke-Otto ${ }^{6}$, \\ Klaus Kapelari ${ }^{7}$, Reinhard W. Holl ${ }^{2}$, Joachim Woelfle ${ }^{8}$ and Markus Bettendorf ${ }^{1}$
}

Citation: Thomann, J.; Tittel, S.R.; Voss, E.; Oeverink, R.; Palm, K.; Fricke-Otto, S.; Kapelari, K.; Holl, R.W.; Woelfle, J.; Bettendorf, M.; et al. Guideline Adherence and Registry Recruitment of Congenital Primary Hypothyroidism: Data from the German Registry for Congenital Hypothyroidism (HypoDok). Int. J. Neonatal Screen. 2021, 7, 10. https://doi.org/10.3390/ijns7010010

Received: 16 January 2021 Accepted: 7 February 2021 Published: 12 February 2021

Publisher's Note: MDPI stays neutral with regard to jurisdictional claims in published maps and institutional affiliations.

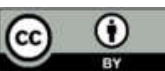

Copyright: (C) 2021 by the authors. Licensee MDPI, Basel, Switzerland. This article is an open access article distributed under the terms and conditions of the Creative Commons Attribution (CC BY) license (http://creativecommons.org/licenses/by/4.0/).
1 Division of Paediatric Endocrinology and Diabetes, University Children's Hospital Heidelberg, 69120 Heidelberg, Germany; markus.bettendorf@med.uni-heidelberg.de

2 Institute of Epidemiology and Medical Biometry, Central Institute for Biomedical Technology, Ulm University, 89081 Ulm, Germany; sascha.tittel@uni-ulm.de (S.R.T.); reinhard.holl@uni-ulm.de (R.W.H.)

3 Cnopfsche Kinderklinik, 90419 Nürnberg, Germany; egbert.voss@diakoneo.de

4 Medicover Paediatric Endocrinology, 26122 Oldenburg, Germany; rudolf.oeverink@medicover.de

5 Department of Paediatrics, University Hospital Magdeburg, 39120 Magdeburg, Germany; Katja.Palm@med.ovgu.de

6 Childrens Hospital Krefeld, 47805 Krefeld, Germany; susanne.fricke-otto@helios-gesundheit.de

7 Division of Paediatric Endocrinology and Diabetes, University Hospital Innsbruck, 6020 Innsbruck, Austria; klaus.kapelari@i-med.ac.at

8 Department of Paediatrics, University Hospital Erlangen, 91054 Erlangen, Germany; Joachim.Woelfle@uk-erlangen.de

* Correspondence: julia.thomann@email.de

\begin{abstract}
Neonatal screening for congenital primary hypothyroidism $(\mathrm{CH})$ is mandatory in Germany but medical care thereafter remains inconsistent. Therefore, the registry HypoDok of the German Society of Pediatric Endocrinology and Diabetology (DGKED) was analyzed to evaluate the implementation of evidence-based guidelines and to assess the number of included patients. Inclusion criteria were (i) date of birth between 10/2001 and 05/2020 and (ii) increased thyroid-stimulating hormone (TSH) at screening and/or confirmation. The cohort was divided into before (A) and after (B) guideline publication in 02/2011, to assess the guideline's influence on medical care. A total of 659 patients were analyzed as group $\mathrm{A}(n=327)$ and group $\mathrm{B}(n=332)$ representing $17.5 \%$ and $10.3 \%$ of $\mathrm{CH}$ patients identified in the German and Austrian neonatal screening program during the respective time period. Treatment start and thyroxine doses were similar in both groups and consistent with recommendations. Regular follow-ups were documented. In the first three years of life, less than half of the patients underwent audiometry; developmental assessment was performed in $49.3 \%$ (A) and $24.8 \%$ (B) $(p<0.01)$. Documentation of $\mathrm{CH}$ patient care by pediatric endocrinologists seemed to be established, however, it reflected only a minority of the affected patients. Therefore, comprehensive documentation as an important instrument of quality assurance and evidence-based medicine should be legally enforced and officially funded in order to record, comprehend, and optimize care and outcome in patients with rare diseases such as $\mathrm{CH}$.
\end{abstract}

Keywords: standardized documentation; quality assurance; longitudinal comparison; multicenter database

\section{Introduction}

Congenital primary hypothyroidism $(\mathrm{CH})$ as a rare disease is the most common endocrine disease with an overall prevalence of 1:2000-3000 in Europe. CH prevalence shows regional heterogeneity within Europe with recent studies reporting increasing 
higher incidences between 1:1000 and 1:1500 in Macedonia and parts of Italy [1,2]. Between 2004 and 2017, 160 to $280 \mathrm{CH}$ patients were detected in the neonatal screening in Germany per year [3].

After introduction of the neonatal screening in Germany and Austria in the 1970s, the symptoms of $\mathrm{CH}$ such as growth retardation and delay of psychomotor development could be prevented by an early treatment start with levothyroxine (L-T4) [4,5].

Guidelines were introduced to harmonise $\mathrm{CH}$ treatment strategies and allow evidence-based patient care [6]. Circulation and compulsory implementation of medical guidelines in clinical care remain limited [7]. Adherence to clinical guidelines varies considerably. Reinforcement and education are essential to enhance overall adherence [8].

The German guideline for $\mathrm{CH}$ [9] was published in 02/2011 in accordance with international recommendations and is currently under revision [10,11]. It is the first German guideline for $\mathrm{CH}$ considering the available evidence up to date. The core statements reflect evidence level S2k (consensus-based guideline) are highlighted in Table 1 and were evaluated with the HypoDok registry. The missing three statements, which aren't evaluated in this manuscript, can be found in Table S1. The Austrian Working Group for Pediatric Endocrinology and Diabetology (APEDÖ) revised its recommendations based on the German guideline in 2017 [12], which is merely a supplement to the existing German guideline.

Table 1. Excerpt of statements included in the German Guideline for Primary Congenital Hypothyroidism (CH) [9].

\begin{tabular}{|c|c|}
\hline Statement 1 & $\begin{array}{l}\text { Initial TSH determination sufficient to initiate confirmatory test- } \\
\text { ing, TRH test not required }\end{array}$ \\
\hline Statement 2 & $\begin{array}{c}\text { Confirmation of } \mathrm{CH} \text { by low serum } \mathrm{fT} 4 \text { or TT4 concentrations } \\
\text { Premature infants/neonates in intensive care: fT4 and TT4 are re- } \\
\text { quired at same time }\end{array}$ \\
\hline Statement 3 & $\begin{array}{l}\text { Ultrasonography of thyroid gland should be performed } \\
\text { Only restrictive use of scintigraphy }\end{array}$ \\
\hline Statement 4 & Hearing test: at confirmation and in the course of treatment \\
\hline Statement 7 & $\begin{array}{c}\text { Start L-T } \mathrm{T}_{4} \text { therapy as early as possible } \\
\text { At least before day } 14\end{array}$ \\
\hline Statement 8 & Initial daily L-thyroxine dose $10 \mu \mathrm{g} / \mathrm{kg}-15 \mu \mathrm{g} / \mathrm{kg}$ \\
\hline Statement 9 & $\begin{array}{c}\text { Timepoints for follow-up: } \\
\text { 1, 2, and } 4 \text { weeks after start of therapy } \\
\text { Subsequently at 3-month intervals during the first two years of } \\
\text { life }\end{array}$ \\
\hline Statement 11 & $\begin{array}{l}\text { Monitoring of psychomotor development: } \\
\text { During the first two years of therapy } \\
\text { Before start of school }\end{array}$ \\
\hline
\end{tabular}

Registries are built to improve patient care and to install instruments of quality control in treating rare endocrine diseases [13]. They also collect data for epidemiological and clinical research activities. The German Society of Pediatric Endocrinology and Diabetology (DGKED) launched the registry HypoDok as an initiative for quality improvement $[14,15]$. The aim of this study was to compare the documented care for patients with $\mathrm{CH}$ to the evidence-based guideline recommendations in order to explore guideline adherence and to assess overall acceptance of HypoDok as a tool for quality assessment.

\section{Patients/Methods}

Based on the anonymized multicenter data collected from the registry, a descriptive evaluation was carried out as an observational study. The data were collected prospectively using the software HypoDok, which was developed at the Institute for Epidemiology and Medical Biometry at Ulm University and distributed free of charge to all interested centers in Germany and Austria [15]. 
The registry was initiated by the German Society for Pediatric Endocrinology and Diabetology (DGKED) on 01/2000 to harmonize the quality of diagnostics and treatment of endocrine disorders across Germany and Austria. For the transfer of pseudonymized data for analysis, consent was obtained from the State Data Protection Commissioner for Saxony-Anhalt. Data collection has been approved centrally by the ethics committee of the University of Magdeburg.

Patient selection and registration were at the discretion of the treating physicians. Patient data was manually extracted from the patient chart and individually entered in a decentralized manner in the local database. Twice a year the local pseudonymized patient data was extracted, exported, and electronically transmitted to the registry in Ulm.

Fifty participating centers in Germany (48) and Austria (2) recorded data of a total of 1630 patients (as of 05/2020) with $\mathrm{CH}$ in HypoDok. Inclusion criteria for this analysis were (i) date of birth between 10/2001 and 05/2020 and (ii) elevated screening TSH and/or elevated serum TSH at confirmation $(>10 \mathrm{mU} / \mathrm{l})$ (Figure 1). An elevated screening TSH (whole blood) was defined in the database when the option "Screening TSH normal: no" was ticked or when values $>15 \mathrm{mU} / \mathrm{l}$ (cut-off) were entered. To gain comparable populations for data analysis nine years after the introduction of the guideline (2011), the period prior to the introduction of the guideline was equally selected as nine years. As a result, a total of 659 HypoDok patients fulfilled the inclusion criteria. For the other patients in the registry, either the date of birth was outside the defined period or the data entry was incomplete/inclusion criteria (ii) were missing.

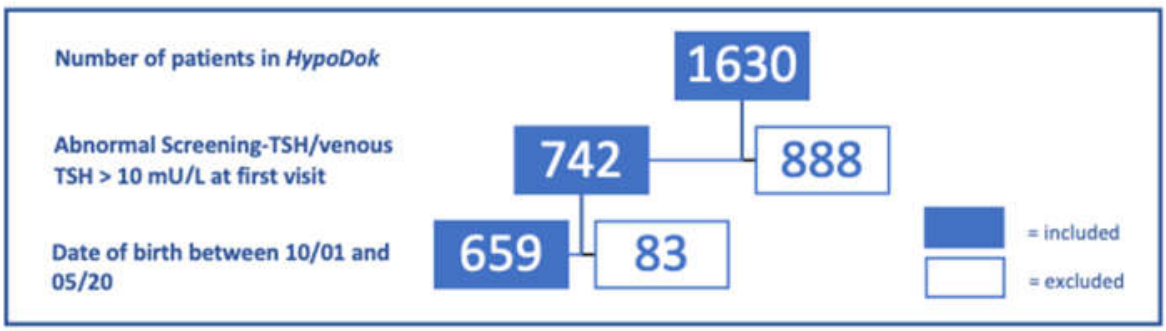

Figure 1. Eligible patients of the HypoDok registry, according to the inclusion criteria of this study (abnormal screening TSH/venous TSH > $10 \mathrm{mU} / \mathrm{L}$ ).

The primary target parameters were defined based on the statements of the German guideline [16]: age at start of therapy [days of life]; serum TSH [mU/l]; serum T4 [ $\mu \mathrm{g} / \mathrm{dl}]$;

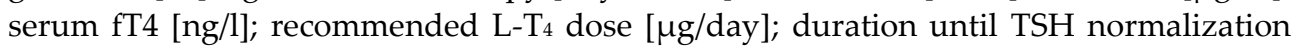
$(<10 \mu \mathrm{U} / \mathrm{mL})$ after start of therapy [days]; developmental assessment result normal [yes/no]; presentation in 1/2/4 weeks after start of therapy [yes/no]; audiometry [yes/no]; thyroid ultrasound [yes/no]; thyroid scintigraphy [yes/no]; thyroid peroxidase antibody (TPO-Ab)/thyroid-stimulating hormone receptor antibody (TSHR-Ab) determined [yes/no]. A normal developmental assessment was defined by the previous assessment of the treatment facility: developmental assessment result normal: yes. The parameters presented in the supplementary material were defined as following: thyroid gland in loco typico [yes/no]; athyreosis [yes/no]; ectopia [yes/no]. Missing values were excluded from analysis.

The target parameters were evaluated separately in a descriptive approach using SAS Version 9.4. The results are presented as median and interquartile range (IQR; continuous variables) or as percent (binary and categorical variables). The differences between the two groups are calculated for the continuous parameters using the Wilcoxon rank sum test and for the percentages using the Chi-square test. The $p$-values were adjusted for multiple testing using the Holm method. A two-sided $p$-value of less than 0.05 was defined to be significant.

To assess the coverage of the registry, the number of patients recorded in HypoDok and included in this study was compared with the number of new diagnoses of congenital 
hypothyroidism detected in the German/Austrian newborn screening per year. Data of the German neonatal screening report for the years 2004-2017 and data from Austria for the years 2015-2019 were available. From the German newborn screening report, the positive predictive value was available for the years 2004-2011 and 2017, specificity was available for the years 2005-2009 and 2017.

\section{Results}

Demographic characteristics of all 659 patients (group A: $n=327$ patients; B: $n=332$ patients) are listed in Table 2. Of these patients, 2.2\% (7 in total) in group A and 6\% (20 in total) in group B were Austrian; $63.6 \%$ and $60.5 \%$ of the patients in groups A and B, respectively, were female.

Table 2. Demographic characteristics of $\mathrm{CH}$ patients, compared before and after guideline appearance (groups A and B).

\begin{tabular}{|c|c|c|c|}
\hline & $\begin{array}{c}\text { Group A } \\
\text { "Before Guideline" } \\
\text { 10/2001-1/2011 } \\
\end{array}$ & $\begin{array}{c}\text { Group B } \\
\text { "After Guideline" } \\
\text { 2/2011-05/2020 }\end{array}$ & $p$-Value \\
\hline Gestational age (weeks) & $\begin{array}{c}40(38 ; 41) \\
(n=314)\end{array}$ & $\begin{array}{l}40(38 ; 41) \\
(n=327)\end{array}$ & 1.00 \\
\hline Birth weight $[\mathrm{g}]$ & $\begin{array}{c}3370(2951 ; 3690) \\
\quad(n=320)\end{array}$ & $\begin{array}{c}3395(2970 ; 3730) \\
\quad(n=330)\end{array}$ & 1.00 \\
\hline Birth length $[\mathrm{cm}]$ & $\begin{array}{c}51(49 ; 53) \\
(n=259)\end{array}$ & $\begin{array}{c}51(49 ; 53) \\
(n=324)\end{array}$ & 1.00 \\
\hline 10 min Apgar score & $\begin{array}{l}10(8 ; 10) \\
(n=322)\end{array}$ & $\begin{array}{l}10(8 ; 10) \\
(n=319)\end{array}$ & 1.00 \\
\hline $\begin{array}{l}\text { Parental target height } \\
\text { (Tanner) }[\mathrm{cm}]\end{array}$ & $\begin{array}{c}172.5(168.5 ; 176.5) \\
(n=271)\end{array}$ & $\begin{array}{c}172.3(168 ; 176) \\
(n=274)\end{array}$ & 1.00 \\
\hline Female $[\%]$ & $\begin{array}{c}63.6 \\
(n=327)\end{array}$ & $\begin{array}{c}60.6 \\
(n=332)\end{array}$ & 1.00 \\
\hline $\begin{array}{c}\text { Premature babies }(<37 \\
\text { weeks) [\%] }\end{array}$ & $\begin{array}{c}8.6 \\
(n=314) \\
\end{array}$ & $\begin{array}{c}10.4 \\
(n=327)\end{array}$ & 1.00 \\
\hline
\end{tabular}

Results are given as median (Q1; Q3) or in \%. Q1 = first quartile, Q3 = third quartile, Statistics: Wilcoxon Rank Sum Test/Chi-Square Test

A comparison of patients in the registry with those from the German neonatal screening registry showed that HypoDok documented an average of $17.5 \%$ of the patients registered by the German neonatal screening with confirmed diagnosis in the years 20042017. Before the introduction of the guideline $19.1 \%$ of the patients were documented; after the introduction of the guideline $15.8 \%$ of the patients were documented. In the latest publication from 2017 , the prevalence of $\mathrm{CH}$ was $1: 2813$. Recall rate $(0.13 \%)$, positive predictive value (PPV) (28.01\%), and specificity (99.91\%) confirm high quality of CH screening. All quality measures obtained in the respective years of analysis of the German newborn screening are provided in Table S2 of the supplementary material.

Austrian data were only available after the introduction of the guideline; here the documentation rate in the HypoDok database was $10.3 \%$ compared to the Austrian neonatal screening registry (Table 3). 
Table 3. Comparison of official number of $\mathrm{CH}$ newborn diagnoses per year in newborn screening and documentation in HypoDok for (a) Germany [3] and (b) Austria [17].

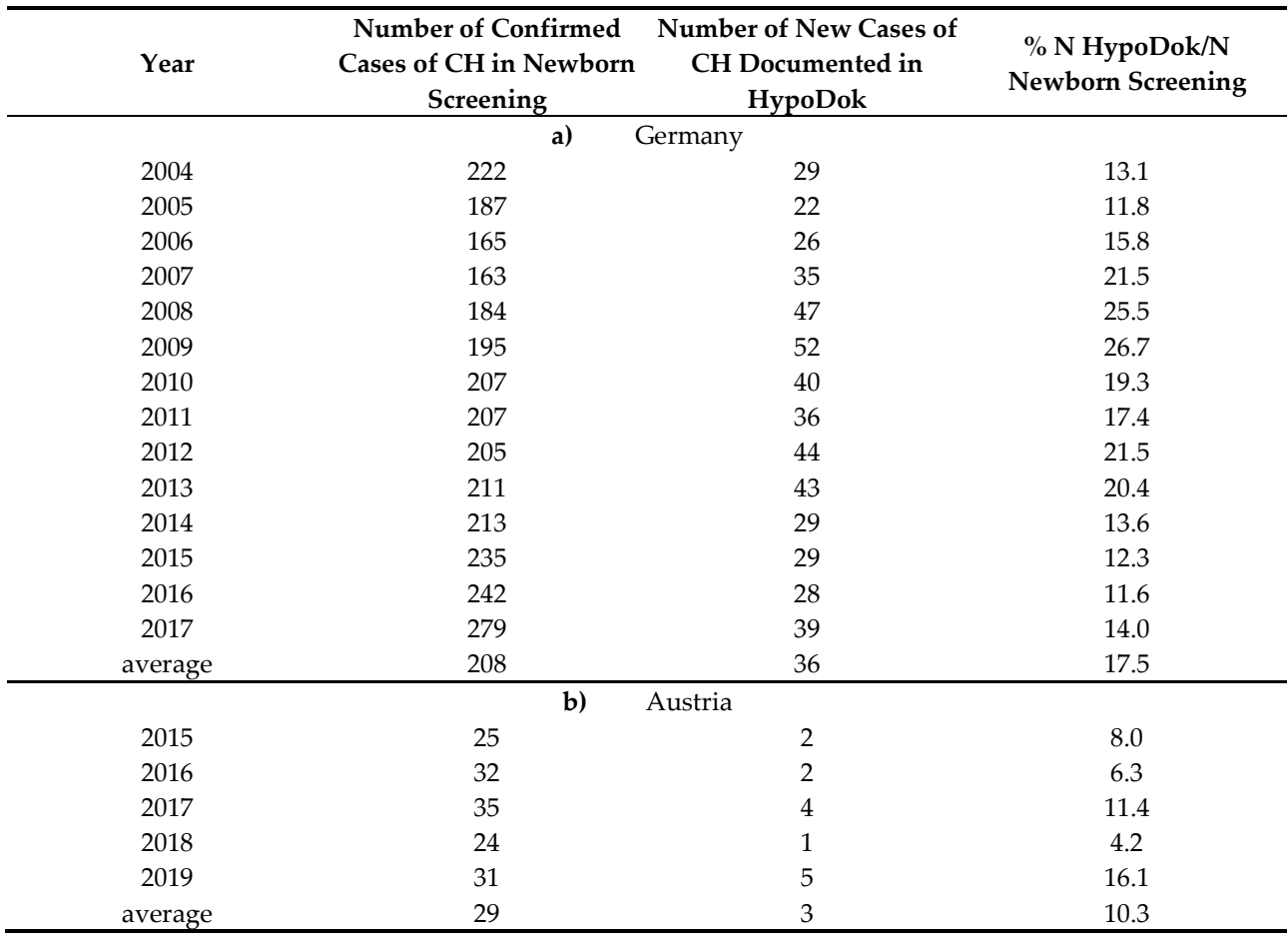

Results are given as absolute numbers and the HypoDok coverage is stated in percent.

For most of the target parameters, not all patients had data available, so the number of evaluated patient data is shown separately:

The complete evaluation of core statements of the guideline with regard to diagnostics is listed in Table 4a. The confirmation of the $\mathrm{CH}$ diagnosis by determination of fT4 and/or TT4 was documented in $34.9 \%(n=327)$ of the patients in group A and in $24.4 \%(n$ $=332)$ of the patients in group B $(p=0.02)$. Audiometry was performed in $24.4 \%$ of patients in group $\mathrm{A}(n=172)$ in the time period 14 days before/after the start of therapy with $\mathrm{L}_{-} \mathrm{T}_{4}$, and in group B in $11.8 \%(n=229)$ within this time interval $(p=0.01)$. Subgrouping of patients based on ultrasonography are shown in the supplementary material in Table S3. Among the patients available for evaluation in this setting, $7.4 \%$ (group $\mathrm{A}, n=54$ ) and $6.7 \%$ (group B, $n=90$ ) had an ectopic located thyroid gland, $24.1 \%$ (group A, $n=58$ ) and $38.5 \%$ (group B, $n=96$ ) showed athyreosis. Gene mutations indicating dyshormonogenesis (mutations in SLC26A4, thyroid peroxidase, and thyreoglobulin gene) are found more frequently compared to genetic alterations associated with dysgenesis (mutation in NKx2.1/TTF1, PAX8, and TSH-receptor gene) in both groups (Table S4).

With no significant differences between the groups initially, therapy was carried out according to the guidelines as shown in Table $4 \mathrm{~b}$.

Table 4c shows the evaluation of the guideline's core statements regarding treatment monitoring. A significant difference was found with regard to the evaluation of psychomotor development over the course of treatment; $49.3 \%$ of patients (group A, $n=302$ ) and $24.8 \%$ of patients (group B, $n=327)(p<0.001)$ were tested, respectively. 
Table 4. Description and comparison of both groups according to the guideline recommendations: (a) diagnostics, (b) treatment, (c) treatment monitoring.

\begin{tabular}{|c|c|c|c|}
\hline & $\begin{array}{c}\text { Group A } \\
\text { "Before Guideline" } \\
\text { 10/2001-1/2011 } \\
\end{array}$ & $\begin{array}{c}\text { Group B } \\
\text { "After Guideline" } \\
\text { 2/2011-05/2020 } \\
\end{array}$ & $p$-Value \\
\hline \multicolumn{4}{|c|}{ a) Diagnostics } \\
\hline $\begin{array}{c}\text { TT4 and/or fT4 } \\
\text { determined at diagnosis } \\
{[\%]^{+}}\end{array}$ & $\begin{array}{c}34.9^{*} \\
(n=327)\end{array}$ & $\begin{array}{c}24.4^{*} \\
(n=332)\end{array}$ & 0.02 \\
\hline $\begin{array}{l}\text { Serum TSH determined } \\
\text { at diagnosis [\%] }{ }^{+}\end{array}$ & $\begin{array}{c}36.1^{*} \\
(n=327)\end{array}$ & $\begin{array}{c}23.2^{*} \\
(n=332)\end{array}$ & 0.002 \\
\hline $\begin{array}{l}\text { Ultrasonography } \\
\text { performed [\%] }\end{array}$ & $\begin{array}{c}92.6 \\
(n=323)\end{array}$ & $\begin{array}{c}92.1 \\
(n=328)\end{array}$ & 0.86 \\
\hline $\begin{array}{c}\text { Scintigraphy performed } \\
{[\%]}\end{array}$ & $\begin{array}{c}5.0 \\
(n=318)\end{array}$ & $\begin{array}{c}1.6 \\
(n=309)\end{array}$ & 0.17 \\
\hline $\begin{array}{l}\text { Hearing test } 14 \text { days } \\
\text { around start of } \\
\text { treatment }[\%]\end{array}$ & $\begin{array}{c}24.4 * \\
(n=172)\end{array}$ & $\begin{array}{c}11.8 * \\
(n=229)\end{array}$ & 0.01 \\
\hline \multicolumn{4}{|c|}{ b) Treatment } \\
\hline $\begin{array}{l}\text { Age at start of treatment } \\
{[\mathrm{d}]}\end{array}$ & $\begin{array}{c}6(5 ; 9) \\
(n=316)\end{array}$ & $\begin{array}{c}6(5 ; 8) \\
(n=318)\end{array}$ & 0.55 \\
\hline $\begin{array}{c}\text { Dose of L-T4 at start } \\
{[\mu \mathrm{g} / \mathrm{d}]}\end{array}$ & $\begin{array}{c}50(50 ; 50) \\
(n=122)\end{array}$ & $\begin{array}{c}50(50 ; 50) \\
(n=131)\end{array}$ & 1.00 \\
\hline \multicolumn{4}{|c|}{ c) Treatment monitoring } \\
\hline $\begin{array}{c}\text { Follow-ups during first } \\
\text { year of life }[n]\end{array}$ & $\begin{array}{c}5(3 ; 7) \\
(n=293)\end{array}$ & $\begin{array}{c}5(3 ; 7) \\
(n=320)\end{array}$ & 0.58 \\
\hline $\begin{array}{l}\text { Follow-ups during } \\
\text { second year of life }[n]\end{array}$ & $\begin{array}{l}3(2 ; 4) \\
(n=255)\end{array}$ & $\begin{array}{l}3(2 ; 4) \\
(n=259)\end{array}$ & 0.33 \\
\hline $\begin{array}{c}\text { Follow-up } 1 \text { week after } \\
\text { start of treatment [\%] }\end{array}$ & $\begin{array}{c}24.2 \\
(n=327)\end{array}$ & $\begin{array}{c}32.5 \\
(n=332)\end{array}$ & 0.17 \\
\hline $\begin{array}{c}\text { Follow-up } 2 \text { weeks after } \\
\text { start of treatment [\%] }\end{array}$ & $\begin{array}{c}31.2 \\
(n=327)\end{array}$ & $\begin{array}{c}38.0 \\
(n=332)\end{array}$ & 0.41 \\
\hline $\begin{array}{c}\text { Follow-up 3-4 weeks } \\
\text { after start of treatment } \\
{[\%]}\end{array}$ & $\begin{array}{c}34.0 \\
(n=327)\end{array}$ & $\begin{array}{c}41.9 \\
(n=332)\end{array}$ & 0.29 \\
\hline $\begin{array}{c}\text { Hearing test performed } \\
\text { within the first } 3 \text { years } \\
\text { of life }(\%)\end{array}$ & $\begin{array}{c}46.4 \\
(=276)\end{array}$ & $\begin{array}{c}40.0 \\
(n=320)\end{array}$ & 0.58 \\
\hline $\begin{array}{c}\text { Developmental } \\
\text { assessment performed } \\
{[\%]} \\
\end{array}$ & $\begin{array}{c}49.3^{*} \\
(n=302)\end{array}$ & $\begin{array}{c}24.8^{*} \\
(n=327)\end{array}$ & $<0.001$ \\
\hline
\end{tabular}

Results are given as median (Q1; Q3) or in \%. Q1 = first quartile, Q3 = third quartile, statistics: Wilcoxon Rank Sum Test/Chi-Square Test, ${ }^{*} p<0.01,+=$ even though "serum TSH determined at diagnosis" is part of the inclusion criteria for $\mathrm{CH}$, the percentage of documented measurements is low as "abnormal screening TSH" is sufficient for patient's inclusion in HypoDok. A documentation gap is to be assumed, since confirmatory testing is essential for diagnosis.

\section{Discussion}

Our multicenter study compared $\mathrm{CH}$ patient care documented in HypoDok with evidence-based recommendations. The majority of the surrogate parameters which assessed the adherence to the core statements were comparable in both groups, irrespective of guideline publication. However, a few significant differences between the two cohorts before and after guideline introduction were apparent. This persistent high level of care can be partly explained by the fact that the data of the registry is derived from pediatric endocrinologists, who were directly or indirectly involved in its development as members of the guideline-developing professional society. The present results were derived from centers of pediatric endocrinology representing only a minority of all $\mathrm{CH}$ patients in Germany and Austria and may therefore carry a selection bias.

HypoDok partly documented the recommendations regarding diagnostics (structural quality) as well as the implementation of therapy control (process quality). The low 
percentage of patients with documented TT4/fT4 serum concentration at initial diagnosis was one example of documentation gap, as low TT4/fT4 levels are a requirement for diagnostic confirmation. This documentation gap may arise due to a structural fault of the database, in that the date of diagnosis can be entered without underlying TT4/fT4 levels.

Another example was the low number of documented hearing tests at the start of treatment, although newborn hearing screening has been a standard service of public health insurance since 01/2009 in Germany and has been regularly reimbursed since 10/2010 [18]. This problem of incomplete documentation in HypoDok, especially at the beginning of treatment, is well known and has already been described by Ellerbroek et al. [14]. The reason for this may be that many patients were only referred to pediatric endocrinologists within the course of the first months, as the guideline only recommends referral within three months; retrospective documentation occurred in only $1 / 3$ of these patients. This clearly demonstrates the importance of strengthening HypoDok's awareness also outside the professional society to a wider spectrum of pediatricians combined with promoting and rewarding $\mathrm{CH}$ documentation, for example, through references within a revised guideline or short notes in journals. Currently, the registry is known mainly within the professional society, through presentations at the annual meetings and its presentation online which aims to target a larger audience [15].

Furthermore, improved documentation of psychomotor developmental assessment is required, especially in group B (24.8\%; group A $49.3 \%$ ). It may be assumed that these assessments were only carried out during the course of therapy if there was a clear clinical indication for developmental retardation. Experienced examiners preselect patients who need a formal assessment, which is, however, not according to current guideline recommendations. The rate of developmental assessments may be underestimated in group B, as some patients are still very young and therefore not all data have been collected so far. Further reasons why psychomotor development has not been regularly checked may be lacking compliance of the patient's family. This may be due to fear of receiving an unfavorable result, a lack of understanding of the importance of the test, and the time required for the extensive testing procedure [14]. Here, the implementation of shorter screening tests could increase patient compliance.

In general, a very variable level of adherence to existing guidelines has already been observed by the treating physicians for a wide range of pediatric diseases. For example, guideline adherence regarding the use of antibiotics in infectious disease is a highly investigated subject [19-21]. These studies showed no change of management in urinary tract infections after introduction of the guideline, whereas the use of antibiotics in community-acquired pneumonia was evidence-based. Overall, it could be shown that noncompliance to evidence-based recommendations carries risks.

Vezzani et al. examined guideline adherence in adult patients with primary hypothyroidism [22]. Here, a satisfactory adherence to the European recommendations was found, with the exception of the $\mathrm{L}-\mathrm{T}_{4}$ starting dose.

Clinical practice guidelines are important tools to practice evidence-based medicine. This was also concluded in a review using examples of pediatric endocrinologic disorders [23]. The successful integration of guideline recommendations can lead to a high, uniform standard of care, save financial resources, and improve patient outcome [24]: James et al. exemplified this through the study of the guideline's use for the treatment of acute respiratory distress syndrome.

The aim to improve guideline implementation should also include the evaluation of patient compliance. Provision of practice aids like checklists or reminders for clinicians and implementation of diaries for patients may improve the problem next to a clear documentation of patient history by healthcare providers [25]. Matlock et al. followed this two-sided approach and presented methods to equally promote guideline adherence by improvement of patient care through the responsible physicians and also in a $\mathrm{CH}$ patientbased manner [26]: these included compiling and continuation of patient records in a database, and education programs of treating physicians and patient families on guideline 
recommendations. Furthermore, patient registries should also be strengthened as a suitable instrument for quality assurance [27].

The percentage of included patients in the HypoDok registry shows that the documented guideline adherence and the registry implementation do not strongly correlate, thus indicating a lack of documented adherence to the guidelines. This could be improved by specifically mentioning the existence of the registry in the guideline, which is currently being revised. At present, the registry is mainly known by pediatric endocrinologists through presentations during conferences of the professional society. However, it should also be promoted among general pediatricians (e.g., by reference in the guideline). Furthermore, a progressive digitalization of data collection and automated data transfer from the patient file to the registry would help to close the documentation gap.

As far as a deduction from documented adherence to actual patient adherence can be made, the HypoDok registry documented a satisfactory adherence to the core statements of the guideline regarding treatment. Thus, the basic preconditions for achieving the best possible patient outcome with adequate therapy were given in both cohorts [2830]. The adherence concerning diagnostics and treatment monitoring by professionals, however, can be improved in both groups. Also, guideline recommendations on developmental assessment in routine care might require re-evaluation. The relationship between severity of illness and compliance was not assessed here. This would be an important aspect to be investigated in further studies.

Overall, the results cannot easily be transferred to the overall quality of care of patients with $\mathrm{CH}$ in Germany and Austria, as only $17.5 \%$ of expected patients with $\mathrm{CH}$ in Germany and even $10.3 \%$ in Austria are currently documented in HypoDok at the time period analyzed here. This results in a selection bias. This low reporting frequency is due to the fact that the database is known and used among experts (pediatric endocrinologists), but not widely used by pediatricians in private practice. This could indicate that a significant number of patients with $\mathrm{CH}$ are not seen by pediatric endocrinologists. The use of the HypoDok registry should be seen as an opportunity to document and ensure the quality of care for patients with $\mathrm{CH}$ and to adapt it to current clinical standards. This way, the treating physician can also compare and adapt patient care with the existing data on the basis of regular database reports.

So far only a few genetic alterations causing $\mathrm{CH}$ have been discovered and genetic testing in $\mathrm{CH}$ remains scarcely available in routine diagnostics (group A $n=11$, group B $n$ $=13$ ). General implementation of genetic testing in $\mathrm{CH}$ in general patient care will increase over the course of the following years. Compiling of genetic sequencing data combined with clinical information and phenotypic data including blood tests could further help to subtype patients suffering from $\mathrm{CH}$ into clinically relevant subgroups.

Overall, management of patient data in databases has not only been identified by the professional society as one of the appropriate instruments for quality assurance. Administrative bodies such as the European Commission or the National Institute of Health also started programs for rare diseases [31]. One example is the European initiative of European Reference Networks (ERN) for different specialities like Endo-ERN for rare endocrine conditions in order to share knowledge to assure and maintain high level of patient care across Europe. As part of this initiative, patient cohort documentation in databases in the case of rare diseases such as $\mathrm{CH}$ is important to ensure structural quality [32,33]. In this context it would be additionally helpful to create a network of accredited regional centers for comprehensive $\mathrm{CH}$ management in childhood, closely linked to neonatal screening centers and primary care pediatricians. Furthermore, center-specific obligation for documentation will have to be strengthened, for example, by means of financial incentives. The authors acknowledge that the current setup of the registry (local documentation with periodic extraction of pseudonymized data) may not be optimal for pediatricians taking care of only few patients with $\mathrm{CH}$. Long-lasting adherence to guidelines and respective documentation remains difficult, since in principle, it is easier to motivate participating professionals and patients over a limited period of time [34]. 
Finally, a legal requirement to keep these patients in registries should be discussed. As the low number of documented $\mathrm{CH}$ patients shows, the implementation of the guideline recommendations of the professional society can only be checked and improved by either obligation or standardized acquisition of data in order to guarantee adequate care. The fact that legal requirements and financial support by the state are helpful in this respect is not only reflected in the reporting frequency of newborn screening, but also in other fields of pediatrics. For example, in oncology, approximately $95 \%$ of childhood cancers are documented in the German Childhood Cancer Registry by appropriate legal requirements [35].

\section{Conclusions}

In summary, the here presented data suggest that in both groups, a guideline-adherent treatment initiation for $\mathrm{CH}$ is implemented. This is the prerequisite condition to achieve a regular physical and psychomotor development in patients with $\mathrm{CH}$. However, direct documentation of psychomotor development seems difficult in routine care. HypoDok can currently only monitor a small proportion of affected patients, primarily those treated by pediatric endocrinologists. In addition, the assessment of guideline adherence based on the available data should be considered with caution because of the suggested documentation gap. In order to maintain the best possible standard of care, this rare disease should be treated in a center with expertise in pediatric endocrinology [9]. In order to monitor and further optimize care, more complete documentation in a registry designed for this purpose such as HypoDok is desirable. Here, support through development of law-enforced requirements in addition to a higher level of awareness of HypoDok may increase the frequency of documentation.

Supplementary Materials: The following are available online at www.mdpi.com//7/1/10/s1, Table S1: Statements of the German Guideline for Primary Congenital Hypothyroidism $(\mathrm{CH})$ which were not further examined in the present manuscript, Table S2: Additional data on German newborn screening, Table S3: Morphology of thyroid gland, examined via sonography, divided before and after guideline appearance (groups A and B), Table S4: Genetic findings indicating a) dysgenesis or b) dyshormonogenesis, divided before and after guideline appearance (groups A and B).

Author Contributions: Conceptualization, J.T., M.B., S.R.T., and R.W.H.; analysis and interpretation of data, J.T., M.B., S.R.T., J.W., and R.W.H.; Writing-Original Draft Preparation: J.T. and M.B.; Writing-Review \& Editing: S.R.T., R.W.H., J.W., E.V., R.O., K.P., S.F.-O., and K.K.; administration of HypoDok registry, S.R.T. and R.W.H.; data entry, J.W., E.V., R.O., K.P., S.F.-O., and K.K. All authors have read and agreed to the published version of the manuscript.

Funding: This research received no external funding.

Institutional Review Board Statement: The study was conducted according to the guidelines of the Declaration of Helsinki and approved by the ethics committee of the University of Magdeburg.

Informed Consent Statement: Not applicable.

Data Availability Statement: The datasets generated and analyzed prospectively in the registry HypoDok are available in the HypoDok repository, https://buster.zibmt.uni-ulm.de/projekte/Hypothyreose/update.

Acknowledgments: We highly acknowledge the work of all clinicians who helped to set up the HypoDok database through their documentation.

Conflicts of Interest: The authors declare no conflict of interest.

\section{Abbreviations}

$\mathrm{Ab}=$ antibody

APEDÖ = Austrian Working Group for Pediatric Endocrinology and Diabetology

$\mathrm{AWMF}=$ Association of the Scientific Medical Societies of Germany

$\mathrm{CH}=$ congenital primary hypothyroidism 


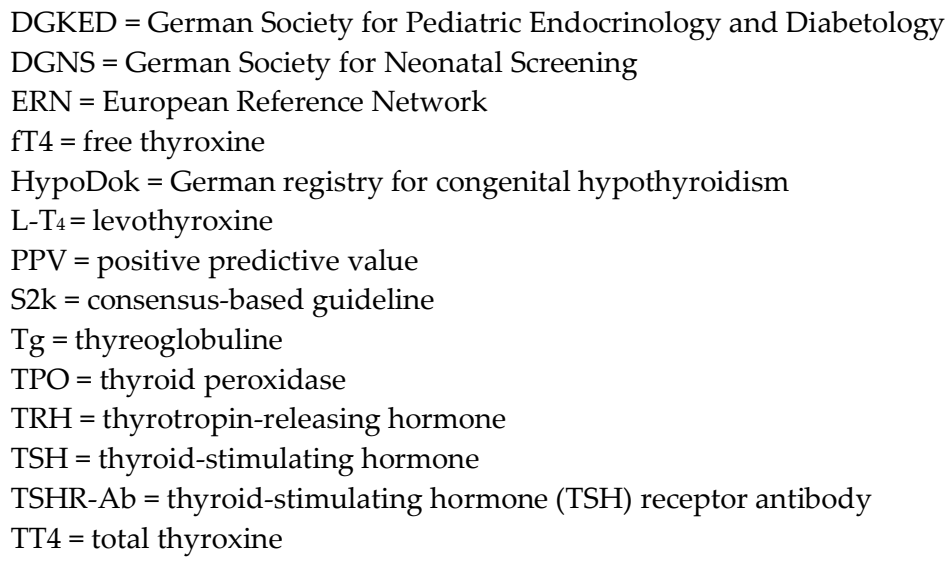

\section{References}

1. Zdraveska, N.; Kocova, M.; Nicholas, A.K.; Anastasovska, V.; Schoenmakers, N. Genetics of Gland-in-situ or Hypoplastic Congenital Hypothyroidism in Macedonia. Front. Endocrinol. 2020, 11, 413, doi:10.3389/fendo.2020.00413.

2. Tuli, G.; Munarin, J.; Tessaris, D.; Matarazzo, P.; Einaudi, S.; de Sanctis, L. Incidence of primary congenital hypothyroidism and relationship between diagnostic categories and associated malformations. Endocrine 2020, doi:10.1007/s12020-02002370-w.

3. Deutsche Gesellschaft für Neugeborenenscreening e.V. DGNS Screeningreports 2004-2017. Availabe online: http://www.screening-dgns.de/reports.php (accessed on 15 October 2020).

4. Bettendorf, M. Thyroid disorders in children from birth to adolescence. Eur. J. Nucl. Med. Mol. Imaging 2002, 29 (Suppl. 2), S439-S446, doi:10.1007/s00259-002-0905-3.

5. Peters, C.; van Trotsenburg, A.S.P.; Schoenmakers, N. DIAGNOSIS OF ENDOCRINE DISEASE: Congenital hypothyroidism: Update and perspectives. Eur. J. Endocrinol. 2018, 179, R297-R317, doi:10.1530/EJE-18-0383.

6. Institute of Medicine. Knowing What Works in Health Care: A Roadmap for the Nation; The National Academies Press: Washington, DC, USA, 2008; p. 278, doi:10.17226/12038.

7. Lesho, E.P.; Myers, C.P.; Ott, M.; Winslow, C.; Brown, J.E. Do clinical practice guidelines improve processes or outcomes in primary care? Mil. Med. 2005, 170, 243-246, doi:10.7205/milmed.170.3.243.

8. Barth, J.H.; Misra, S.; Aakre, K.M.; Langlois, M.R.; Watine, J.; Twomey, P.J.; Oosterhuis, W.P. Why are clinical practice guidelines not followed? Clin. Chem. Lab. Med. 2016, 54, 1133-1139, doi:10.1515/cclm-2015-0871.

9. Krude, H. Diagnostik, Therapie und Verlaufskontrolle der Primären Angeborenen Hypothyreose. Availabe online: https://www.awmf.org/uploads/tx_szleitlinien/027-0171_S2k_Primaere_Angeborene_Hypothyreose_2011-abgelaufen.pdf (accessed on 20 September 2020).

10. Rose, S.R.; Brown, R.S.; Foley, T.; Kaplowitz, P.B.; Kaye, C.I.; Sundararajan, S. Update of newborn screening and therapy for congenital hypothyroidism. Pediatrics 2006, 117, 2290-2303, doi:10.1542/peds.2006-0915.

11. Leger, J.; Olivieri, A.; Donaldson, M.; Torresani, T.; Krude, H.; van Vliet, G.; Polak, M.; Butler, G.; Espe Pes Slep Jspe Apeg Appes, I.; Congenital Hypothyroidism Consensus Conference, G. European Society for Paediatric Endocrinology consensus guidelines on screening, diagnosis, and management of congenital hypothyroidism. J. Clin. Endocrinol. Metab. 2014, 99, 363384, doi:10.1210/jc.2013-1891.

12. Blümel, P.; Köstl, G. Konnatale Hypothyreose-Diagnose und Behandlungsempfehlung der APEDÖ. J. Für Klin. Endokrinol. Stoffwechs. 2019, 12, 14-18, doi:10.1007/s41969-019-0057-8.

13. Ali, S.R.; Bryce, J.; Cools, M.; Korbonits, M.; Beun, J.G.; Taruscio, D.; Danne, T.; Dattani, M.; Dekkers, O.M.; Linglart, A.; et al. The current landscape of European registries for rare endocrine conditions. Eur. J. Endocrinol. 2019, 180, 89-98, doi:10.1530/EJE-18-0861.

14. Ellerbroek, V.L.; Bonfig, W.; Dorr, H.G.; Bettendorf, M.; Hauffa, B.; Fricke-Otto, S.; Rohrer, T.; Reschke, F.; Schonau, E.; Schwab, K.O.; et al. Long-term Surveillance of Children with Congenital Hypothyroidism: Data from the German Registry for Congenital Hypothyroidism (AQUAPE “Hypo Dok”). Klin. Padiatr. 2015, 227, 199-205, doi:10.1055/s-0035-1549978.

15. Institute of Epidemiology and Medical Biometry, University of Ulm. Anonymized AQUAPE/Hypothyroidism-Data Export HypoDok. Availabe online: https://buster.zibmt.uni-ulm.de/projekte/Hypothyreose/software (accessed on 30 April 2020).

16. Gruters, A.; Krude, H. Detection and Treatment of Congenital Hypothyroidism. Nat. Rev. Endocrinol. 2011, 8, 104-113, doi:10.1038/nrendo.2011.160.

17. Universitätsklinik für Kinder- und Jugendheilkunde, Medizinische Universität Wien. Zahlen und Daten NeugeborenenScreening. https://www.meduniwien.ac.at/hp/fileadmin/neugeborenenscreening/pdf/Zahlen_und_Daten_aus_dem_Neugeborenensc reening_2019.pdf (accessed on 8 January 2021). 
18. Gesundheit, B.F. Einführung eines Neugeborenen-Hörscreenings. Availabe online: https://www.g-ba.de/beschluesse/681/ (accessed on 7 May 2020).

19. Inouye, B.M.; Dionise, Z.R.; Jiang, R.; Wolf, S.; Nicholl, L.; Pomann, G.M.; Wiener, J.S.; Purves, J.T.; Routh, J.C. National Imaging and Antibiotic Practice Patterns in Children Presenting With Urinary Tract Infection to Community Practices: Little Impact From the American Academy of Pediatrics Guidelines? Clin. Pediatr. 2019, 58, 1302-1308, doi:10.1177/0009922819853003.

20. McMullan, B.J.; Hall, L.; James, R.; Mostaghim, M.; Jones, C.A.; Konecny, P.; Blyth, C.C.; Thursky, K.A. Antibiotic appropriateness and guideline adherence in hospitalized children: Results of a nationwide study. J. Antimicrob. Chemother. 2019, doi:10.1093/jac/dkz474.

21. Newman, R.E.; Hedican, E.B.; Herigon, J.C.; Williams, D.D.; Williams, A.R.; Newland, J.G. Impact of a guideline on management of children hospitalized with community-acquired pneumonia. Pediatrics 2012, 129, e597-e604, doi:10.1542/peds.2011-1533.

22. Vezzani, S.; Giannetta, E.; Altieri, B.; Barbonetti, A.; Bellastella, G.; Certo, R.; Cignarelli, A.; Cinti, F.; D'Andrea, S.; Di Dalmazi, G.; et al. An Italian Survey of Compliance with Major Guidelines for L-Thyroxine of Primary Hypothyroidism. Endocr. Pract. 2018, 24, 419-428, doi:10.4158/EP-2017-0159.

23. Kelnar, C.J. Evidence-based child health: SIGN and NICE. Arch. Dis. Child. Educ. Pract. Ed. 2008, 93, 190-198, doi:10.1136/adc.2007.131607.

24. James, B.C.; Hammond, M.E. The challenge of variation in medical practice. Arch. Pathol. Lab. Med. 2000, 124, 1001-1003, doi:10.1043/0003-9985(2000)124<1001:TCOVIM>2.0.CO;2.

25. Mäkelä, M. Changing Professional Practice-Theory and Practice of Clinical Guidelines Implementation; DSI: Copenhagen, Denmark, 1999.

26. Matlock, K.A.; Corathers, S.D.; Yayah Jones, N.H. Untreated congenital hypothyroidism due to loss to follow-up: Developing preventive strategies through quality improvement. J. Pediatr. Endocrinol. Metab. 2018, 31, 987-994, doi:10.1515/jpem-2018-0149.

27. Schechter, M.S.; Fink, A.K.; Homa, K.; Goss, C.H. The Cystic Fibrosis Foundation Patient Registry as a tool for use in quality improvement. BMJ Qual. Saf. 2014, 23 (Suppl. 1), i9-i14, doi:10.1136/bmjqs-2013-002378.

28. Bongers-Schokking, J.J.; de Muinck Keizer-Schrama, S.M. Influence of timing and dose of thyroid hormone replacement on mental, psychomotor, and behavioral development in children with congenital hypothyroidism. J. Pediatr. 2005, 147, 768774, doi:10.1016/j.jpeds.2005.09.031.

29. Oerbeck, B.; Sundet, K.; Kase, B.F.; Heyerdahl, S. Congenital hypothyroidism: Influence of disease severity and L-thyroxine treatment on intellectual, motor, and school-associated outcomes in young adults. Pediatrics 2003, 112, 923-930, doi:10.1542/peds.112.4.923.

30. Aleksander, P.E.; Bruckner-Spieler, M.; Stoehr, A.M.; Lankes, E.; Kuhnen, P.; Schnabel, D.; Ernert, A.; Stablein, W.; Craig, M.E.; Blankenstein, O.; et al. Mean High-Dose 1-Thyroxine Treatment Is Efficient and Safe to Achieve a Normal IQ in Young Adult Patients With Congenital Hypothyroidism. J. Clin. Endocrinol. Metab. 2018, 103, 1459-1469, doi:10.1210/jc.2017-01937.

31. National Center for Advancing Translational Sciences. RaDaR- Rare Diseases Registry Program. Availabe online: https://registries.ncats.nih.gov/about-radar/ (accessed on 8 January 2021).

32. Ali, S.R.; Bryce, J.; Tan, L.E.; Hiort, O.; Pereira, A.M.; van den Akker, E.L.T.; Appelman-Dijkstra, N.M.; Bertherat, J.; Cools, M.; Dekkers, O.M.; et al. The EuRRECa Project as a Model for Data Access and Governance Policies for Rare Disease Registries That Collect Clinical Outcomes. Int. J. Environ. Res. Public Health 2020, 17, doi:10.3390/ijerph17238743.

33. de Vries, F.; Bruin, M.; Cersosimo, A.; van Beuzekom, C.N.; Ahmed, S.F.; Peeters, R.P.; Biermasz, N.R.; Hiort, O.; Pereira, A.M. An overview of clinical activities in Endo-ERN: The need for alignment of future network criteria. Eur. J. Endocrinol. 2020, 183, 141-148, doi:10.1530/EJE-20-0197.

34. Storf, H.; Stausberg, J.; Kindle, G.; Quadder, B.; Schlangen, M.; Walter, M.C.; Uckert, F.; Wagner, T.O.F.; Strategiegruppe, N.R. Patient registries for rare diseases in Germany: Concept paper of the NAMSE strategy group. Bundesgesundheitsblatt Gesundheitsforschung Gesundheitsschutz 2020, 63, 761-770, doi:10.1007/s00103-020-03151-6.

35. German Childhoood Cancer Registry: Annual Report of $2018 . \quad$ Availabe online: https://www.kinderkrebsregister.de/dkkr/ergebnisse/jahresberichte.html (accessed on 3 August 2020). 